been already noted by the pneumograph. (b) Another stethoscopic result which I have repeatedly observed is that the tracheal treatment checks the abnormal secretion from the broncho-pulmonary surfaces, and this result has been characterised by the diminution or disappearance of the different râles-subcrepitant, cavernous, or simply dry.

After this short exposition of the tracheal method, which, you perceive, may be used not only in tuberculosis but in any chronic broncho-pulmonary disease, I next proceed to give you some clinical demonstrations of the simplicity and efficacy of the process which I employ. I first show you a patient on whom tracheotomy was performed two years ago for syphilitic laryngitis. I remove the tube from his trachea and I give him a tracheal injection through his mouth by the simplified method. You can see the liquid, which is oil coloured red, running out of the opening in his trachea. Finally, I will give the injection to ordinary patients. You will see that this operation is rapid, simple, and not at all disagreeable to them.

\section{ON THE HOURS OF SLEEP AT PUBLIC SCHOOLS,}

BASED ON AN INQUIRY INTO THE ARRANGEMENTS EXISTING IN FORTY OF THE GREA'T PUBLIC SCHOOLS IN ENGLAND AND OTHERS IN THE UNITED STATES OF AMERICA.?

BY T. D. ACLAND, M.A., M.D. Oxon.; F.R.C.P. Lond., PHYSICIAN TO ST. THOMAS'S HOSPITAL AND CONSULTING PHYSICIAN TO THE HOSPITAL FOR DISEASES OF THE CHEST, BROMPTON.

IT may possibly be asked why one who is not a medical officer to a great public school should take up the question as to the hours of sleep which are desirable for boys at school. The explanation is a simple one. My interest was excited by a particular case and during the inquiries which ensued it seemed to me that it might be no bad thing for an outsider to introduce a discussion on this subject, especially if, like myself, he had no preconceived ideas and no traditions to influence him by casting an enticing and romantic haze over practices which belong to a bygone age but which are in many ways opposed to the more enlightened views of modern hygiene. There cannot be any question that sufficient sleep is a matter not only of importance but of vital necessity to the well-being of all young and growing children, especially at that period when the rapid unfolding of new bodily and intellectual functions - makes it more than ever desirable that they should not be subjected to any influence which may retard or prevent the full development of their powers. A physiological question such as the one under consideration, which involves more than a third part of a boy's life, is surely one on which the Medical Officers of Schools' Association may be asked to express an opinion. Judging by some of the correspondence which has lately appeared in the daily press on the subject of our public schools there are still some persons who think that dirt, lack of cubic space, and insufficient food are Spartan conditions which tend to promote hardihood and intelligence, and that cleanlines $=$, good food, ample ventilation, and common-sense regaid for health encourage selfindulgence and coddling. Although much has been done to improve the condition of our great schools during the last 25 years it is within the knowledge of us all that there is still room for improvement, especially in matters relating to health. My object to-day is to discuss with you the question as to the amount of sleep which it is desirable to give to the younger boys during the first two or three years of their life at a public school, when they have not yet become acclimatised to their new conditions and when they are subjected to pressure of various kinds such as they have never before experienced, whilst at the same time they have reached a crisis in their lives which necessitates the most watchful care to enable them to attain to the maximum of intellectual and bodily efficiency.

Much is said about over-pressure in schools and all of us must know of cases in which actual breakdown has occurred. I know of many and my belief, which is shared by others

1 A paper read before the Medical Officers of Schools' Association on May 11th, 1905. who have ample opportunity for observation, is that a part, at any rate, of the harm is done by too little rest being given to the higher nerve centres owing to insufficient or broken sleep. Up to the time when this question first began to interest me I had assumed (as doubtless many have done before) that the hours of sleep in any great school were apportioned on some plan which had been carefully thought out between the medical advisers and the executive, and it came to me as something of a surprise to find that in a school in which the medical officer has for many years strenuously advocated the necessity for giving the boys up to 16 years of age ten hours' sleep a small boy of 13 years was placed in a dormitory in which the prefects' lights were not out and the dormitory was not quiet until 10.30 , the boys being roused again at 6.15 , giving, in fact, only seven and three-quarter hours of quiet.

It is generally held that an average of about eight hours sleep is good for adults after they have attained their full development and during the best years of their active work. Some, of course, require less ; some few require more. It is largely a matter of idiosyncrasy. There is much practical and some experimental evidence on this point. One distinguished member of our profession, a man of great physical strength, whose intellectual power was recognised by all who knew him, when under the full stress of work often required, and took, ten. Another tells' = ke cannot do with less than eight and a half and anothe .ne. Eight hours' sleep seems to be a reasonable avera for an adult when engaged in active work. It is adn.ted by all that the growing boy needs more sleep tha ${ }^{*}$ the adult man. It cannot, therefore, be unreasonable $t$, ask that boys who are just emerging out of childhood, when they are working and playing harder than ever before, should have fuller hours of sleep than those which not unreasonably would be granted to a hard-worked man. "Truth," as Ruskin says, "is not to be discerned by the uneducated senses." A clear perception of what is needed must depend upon previous knowledge and the exercise of trained observation. 'Those who have the care of growing boys ought not to be satisfied that long hours of work and strenuous play, combined with short hours of sleep, are desirable for them without careful inquiry, nor without taking counsel with those who have opportunity of looking a few years ahead and who are able to scan the horizon of the boy's future life after he shall have reached maturity.

I cannot doubt that the trained experience of the physician, who is able not only to watch the effect of school life upon the boy but also to observe its after-effects, is a safer guide in the ultimate decision of all questions relating to health than that of the layman who has not the technical knowledge and whose observation is mainly limited to the four or five years of the boy's public school life. The consequence of lack of repose to the body and central nervous system may entirely escape the notice even of a careful and experienced master. I have been told that it is not noticeable that the younger boys suffer more from illness than the older ones and that they do not show any ill-effects from lack of rest. To an untrained observer nothing may appear to be wrong, whilst all the time the boy may be working under a strain to his nervous system, which, before many years have passed, may work out its nemesis in some neurosis, such as neurasthenia, chorea, or even epilepsy. We unfortunately know only too well that the first positive evidence of nerve strain may indicate damage, the effect of which will last through life. "The mischief," an expert" writes to me, "is that the evil consequences ...... do not alwass show themselves at once, but are cumulative and come to the surface (often) after the boy has left school." I know of such cases, and there can be few here present who have not seen them; and which of us would like to apportion the blame with confidence between overwork, under-sleep, or idiosyncrasy? Surely, if there is a possibility of risk it is wiser to recognise it and not to subject the boy to any avoidable strain which is as unnecessary as it is contrary to well-known physiological laws.

How fallacious deductions made from a limited point o' vitw or with preconceived ideas may prove to be is shown b the following statement of a lay correspondent who writes "What you and those who agitate with you for longer br-

2 Sir James Crichton-Browne, M.D., F.R.S., Lord Cha and Visitor in Lunacy, writer of report on "Overpressure in Eleme "jecSchools," printed by the House of Commons; Vice-President, Ros or Institution, Great Britain. 
of sleep are doing is simply to encourage the luxury and selfindulgence which are eating the heart out of our English boyhood and manhood and which show themselves nowhere more than in the matter of oversleeping." This is a serious statement, if it be true, and is deserving of full consideration. I shall refer to it again later, but as bearing upon the question I may mention that in four schools in which both the master and medical officers give their opinion in each case the master states that he does not think the smaller boys in that particular school need more sleep, whilst the medical officer is of opinion that they do. To ascertain the facts as completely as possible I have, through the kindness of many correspondents (to whom I here tender my sincere thanks), obtained the approximate hours of quiet in the dormitories in 40 of the great schools in England and in five of the largest and best schools in America ${ }^{3}$ (Tables I. and II.) and I have obtained the opinions of a great number of observers in all parts of the country, especially of those who have written on the subject in standard works. I am thus enabled to lay before you a weighty mass of opinion, gathered from masters and medical officers of schools, physiologists, and physicians. From all quarters comes the same reply: growing bovs need from nine to ten hours of sleep, the majority say ten should be given to the younger boys-e.g., from 13 ta 16 years of age-if the body and central nervous syst are to be maintained at their maximum efficiency (see . ble IV. (A)). Here and there, but very rarely, a contrary jinion has been expressed but in no case has any defence on short-i.e., less than nine-hours of sleep been made by $x_{\text {ny }}$ medical officer of a school or physician. In the very few cases in which it has been made it has come from a layman who can hardly be fully acquainted with the medicai side of the question. The fact is that the unanimity of tie replies $I$ have received has caused me some surprise. There has practically been no dissent from the opinion that the younger boys require, and frequently do not get, sufficient rest. If it were not that it seems to be unknown to some and is not acted on by others who have charge of the boys in our great public schools I should not venture to repeat the familiar message but the facts as they exist must be faced.

There are three main points to be considered: (1) the allowance of sleep which is reasonable for growing boys during the first two or three years of their life at a public school; (2) the risk which is incurred by stinting young growing boys of that amount of sleep for which nature makes an imperative demand; and (3) some of the difficulties in the way of obtaining the needful amount of sleep in many public schools.

I will ask you first to consider the question from the point of view of the physiologist. Professor J. G. McKendrick writes to me: "A young growing lad should have ten hours" sleep both during summer and winter. During the time they are at school and college there can be no doubt that the mental efficiency of boys is kept up to the normal standard by plenty of sleep. I have often noticed a jaded appearance when less sleep was obtained than, say, eight or nine hours, whilst the boy will be bright and alert if he has, say, ten hours. ..... I have known men who were no longer boys who still needed nine hours' sleep if they were to do effective work." Another distinguished physiologist, Professor C. S. Sherrington, ${ }^{5}$ writes to me at length, condemning the practice of attempting to run the young boy's life with the same allowance of sleep which he considers necessary for the full-grown adult. He points out that the child's bodily life is run more expensively than the adult's, since bulk increases as the cube and surface as the square the child has, relatively, far more body surface than the adult and has in consequence to produce more body heat to maintain its temperature. This is proved by the fact that the average child gives out about 500 cubic centimetres of $\mathrm{CO}_{2}$ per kilo of body weight as against 300 given out by the adult. The combustion in the child is more active than when growth

iA form of inquiry was sent to all the principal public schools in land and in a large number of instances, where the information not sufficiently exact, subsequentinquiries were made. I am under ep debt of obligation to my many correspondents, some of whom Id like to mention by name, were it not for obvious reasons un-

for McKendrick, M.D., F.R.S., Professor of Physiology fir. irersity of Glasgow, formerly Fullerian Professor of Physiofr." Institution of Great Britain, and writer of the article on br w the "Encyclopædia Britannica."

Protessor Sherrington, M.D., F.R.S., Holt Professor of Phrsio$10 \mathrm{gy}$, Lniversity of Liverpool, chairman of the British Association Committee on school Hygiene. has ceased; and further, there is the additional drain caused by growth and the characteristic restlessness of boyhood; from all of which points, which are incontrovertible, he deduces that solely on physiological grounds the body of the child demands a diurnal balance of repose much greater than that which is required in later life-in short, that boyhood wants longer sleep than does set manhood. "During sleep the chemical processes of the body are reduced in the case of $\mathrm{CO}_{2}$ output to one-fifth, so that the organism during sleep may be said to have its fires banked instead of being run under forced draught. But sleep is not only a respite from chemical change, it is a

TABLE I.-Showing the Approximate Hours of Undisturbed Rest in 40 English Public Sohools.

\begin{tabular}{|c|c|c|c|c|c|}
\hline \multirow{2}{*}{-} & \multicolumn{2}{|c|}{ Younger boys. } & \multicolumn{2}{|c|}{ Older boys. } & \multirow{2}{*}{$\begin{array}{l}\text { Duration of winter } \\
\text { hours. }\end{array}$} \\
\hline & Summer. & Winter. & Summer. & Winter. & \\
\hline 1 & $10 \frac{1}{2}$ & $10 \frac{1}{2}$ & $8 \frac{1}{2}$ & $9 \frac{1}{2}$ & $\begin{array}{l}\text { Same all the year for } \\
\text { juniors. }\end{array}$ \\
\hline 2 & 10 & $10 \frac{1}{4}$ & $9 \frac{1}{4}$ & $9 \frac{1}{2}$ & $\begin{array}{l}\text { Two winter terms, } 24 \\
\text { weeks. }\end{array}$ \\
\hline 3 & $9 \frac{3}{4}$ & $10 \frac{1}{4}$ & $8 \frac{3}{4}$ & $9 \frac{1}{4}$ & ITot stated. \\
\hline 4 & 93 & 10 & $8 \frac{1}{4}$ & $8 \frac{1}{2}$ & About 8 weeks. \\
\hline 5 & $9 \frac{3}{4}$ & $9 \frac{3}{4}$ & $8 \frac{3}{4}$ & $8 \frac{3}{4}$ & Same all the year. \\
\hline 6 & $9 \frac{1}{4}$ & $9 \frac{3}{4}$ & $8 \frac{1}{2}$ & $8 \frac{3}{4}$ & Not stated. \\
\hline 7 & $9 \frac{1}{4}$ & $10 \mathrm{~h} .10 \mathrm{~m}$ & $8 \frac{1}{2}$ & $9 \mathrm{~h} .20 \mathrm{~m}$. & About 14 weeks. \\
\hline 8 & $9 \frac{1}{4}$ & $9 \cdot \frac{1}{2}$ & $9 \frac{1}{4}$ & $9 \frac{1}{2}$ & Not stated. \\
\hline 9 & $9_{\frac{1}{4}}$ & $9 \frac{1}{4}$ & $8 \frac{1}{2}$ & $8 \frac{1}{2}$ & Same all the year. \\
\hline 10 & $9 \frac{1}{4}$ & $9 \frac{1}{2}$ & 83 & $?$ & About 9 weeks. \\
\hline 11 & $9 \frac{1}{4}$ & $9 \frac{1}{4}$ & $9 \frac{1}{4}$ & $9 \mathrm{~J}$ & Same all the year. \\
\hline 12 & 9 & 10 & 8 & 9 & 24 weeks. \\
\hline 13 & 9 & 10 & $8 \frac{1}{2}$ & $9 \frac{1}{2}$ & About 8 weeks. \\
\hline 14 & 9 & 10 & $8 \frac{1}{2}$ & $9 \frac{1}{2}$ & " \\
\hline 15 & 9 & $9 \frac{1}{2}$ & 9 & $9 \frac{1}{2}$ & 24 weeks. \\
\hline 16 & 9 & $9 \frac{1}{2}$ & $8 \frac{1}{2}$ & 9 & About 16 weeks. \\
\hline 17 & 9 & 9 & $8 \frac{1}{2}$ & $8 \frac{1}{2}$ & Same all the year. \\
\hline 18 & 83 & $8 \frac{3}{4}$ & 8 & 8 & , \\
\hline 19 & $8 \mathrm{~h} .40 \mathrm{~m}$. & 912 & 8 h. $40 \mathrm{~m}$ & $9 \frac{1}{2}$ & 24 weeks. \\
\hline 20 & $8 \mathrm{~h} .40 \mathrm{~m}$. & $8 \mathrm{~h} .55 \mathrm{~m}$. & .8 h. $40 \mathrm{~m}$. & $.8 \mathrm{~h} .55 \mathrm{~m}$. & About 8 weeks. \\
\hline 21 & $8 \frac{1}{2}$ & $9 \frac{1}{2}$ & $8 \frac{1}{2}$ & $9 \frac{1}{2}$ & 24 weeks. \\
\hline 22 & $8 \frac{1}{2}$ & $9 \frac{1}{4}$ & $8 \frac{1}{2}$ & $9 \frac{1}{4}$ & $"$, \\
\hline 23 & $8 \frac{1}{2}$ & $9 \frac{1}{4}$ & $8 \frac{1}{2}$ & $9 \frac{1}{4}$ & $"$ \\
\hline 24 & $8 \frac{1}{2}$ & $9 \frac{1}{2}$ & 8 & 9 & About 5 weeks. \\
\hline 25 & $8 \mathrm{~h} .25 \mathrm{~m}$. & $9 \frac{1}{4}$ & $8 \mathrm{~h} .25 \mathrm{~m}$. & $9 \frac{1}{4}$ & About 10 weeks. \\
\hline 26 & $8 \frac{1}{2}$ & $9 \frac{1}{2}$ & $8 \frac{1}{2}$ & $9 \frac{1}{2}$ & Not stated. \\
\hline 27 & $8 \frac{1}{2}$ & 9 & 8 & $8 \frac{1}{2}$ & 24 weeks. \\
\hline 28 & $8 \frac{1}{2}$ & 9 & $7 \frac{1}{2}$ & 8 & About 8 weeks. \\
\hline 29 & $8 \frac{1}{2}$ & 9 & $8 \frac{1}{2}$ & 9 & About 12 w eeks. \\
\hline 30 & $8 \frac{1}{2}$ & 9 & $8 \frac{1}{2}$ & 9 & About 6 weeks. \\
\hline 31 & $8 \frac{1}{2}$ & 83 & $8 \frac{1}{2}$ & 83 & Not stated. \\
\hline 32 & $8 \frac{1}{2}$ & $8 \frac{1}{2}$ & 8 & 8 & Same all the year. \\
\hline 33 & $8 \frac{1}{2}$ & $8 \frac{1}{2}$ & $8 \frac{1}{2}$ & $8 \frac{1}{2}$ & " \\
\hline 34 & $8 \frac{1}{2}$ & $9 \frac{1}{4}$ & $8 \frac{1}{2}$ & $9 \frac{1}{4}$ & A few weeks only. \\
\hline 35 & $8 \frac{1}{4}$ & 9 & $8 \frac{1}{4}$ & 9 & About 18 weeks. \\
\hline 36 & $8 \frac{1}{4}$ & 9 & - & - & 24 n eeks. \\
\hline 37 & $8 \frac{1}{4}$ & $8 \frac{3}{4}$ & $8 \frac{1}{4}$ & $8 \frac{3}{4}$ & Not stated. \\
\hline 38 & $8 \frac{1}{4}$ & $8 \frac{1}{4}$ & $8 \frac{1}{4}$ & $8 \frac{1}{4}$ & Same all the year. \\
\hline 39 & 8 & 9 & 8 & 9 & A few weeks only. \\
\hline 40 & 73 & $8 \frac{1}{4}$ & $7 \frac{3}{4}$ & $8 \frac{1}{4}$ & For some weeks. \\
\hline
\end{tabular}

mechanical rest as well, which is especially of importance during the years of growth. By insufficient rest the growth can be stunted and development retarded. The heart and respiratory mechanism require for their efficient working a diastole (or rest period) equal to their working hours. Most of a boy's growth in stature is done in bed and there mental and physiological recreation goes on most efficiently; without plenty of sleep the activity of the waking day is like a house built on sand-in constant danger of breaking down and giving way." He concludes by saying: "I should put the length of rest in bed demanded 'by small boys'-e.g., boys from 13 to 15 jears-at ten hours and their normal hour for retiring 
at 9 "; and he adds, as is universally adraitted. "the wants of all children are not the same-it is a question of idiosyncrasy."

Thus speaks the physiologist in no uncertain terms. In his opinion there are not two sides to this question. I hear it objected, however, that this is all very well but it is pure theory - the speaker has no practical experience of the education of boys and their actual needs. Far from this being the case, Professor Sherrington is not only a distinguished physiologist but be is also the chairman of a committee appointed by the British Association to report on the conditions of health essential to the carrying on of the work of instruction in schools and for some years he has given special attention to the subject.

TABLE II. (A).--Showing the Hours of Sleep given in Five of the Principal American Schools.

\begin{tabular}{|c|c|c|}
\hline- & Younger boys. & Older boys. \\
\hline 1 & 10 and 93 according to age. & $9 \frac{1}{2} ;$ sixth form 9. \\
\hline 2 & 10 winter, $9 \frac{1}{2}$ summer. & $9 \frac{1}{2}$ winter, 9 summer. \\
\hline 3 & 10 to 9 under 16 years. & 9 from 16 to 18 years. \\
\hline 4 & $10 \frac{1}{4}$ under 15 sears. & $\begin{array}{l}9 \text { hrs. } 20 \text { min. orer } 15 \text { years; sixth } \\
\text { form } 8 \text { hrs. } 55 \text { min. }\end{array}$ \\
\hline 5 & $10 \frac{1}{2}$ to 9 according to age. & Sixth form $8 \frac{1}{2}$ \\
\hline
\end{tabular}

Note. - In none of the above schools is there chapel or school before breakfast at any time during the year.

TABLE II. (B).- Showing the Hours of Sleep given in Certain Training ships and Institutions.

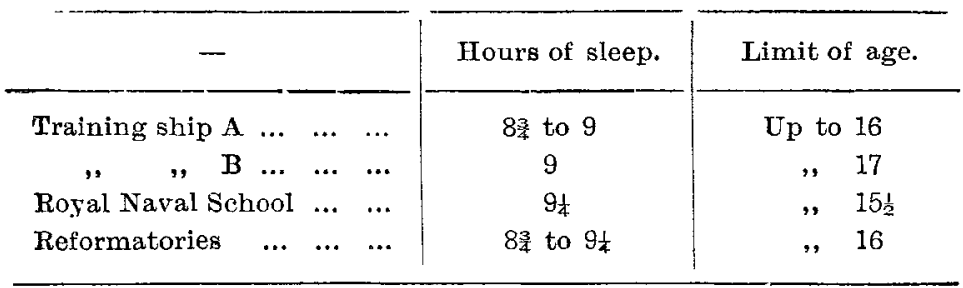

If the words of the man of science cannot carry conviction let the house master in one of the most celebrated schools in England speak. He writes: "On the general principle of giving boys more sleep I am quite with you and will support any reasonable proposal when made for reform." And, further, the headmaster of one of the best schools in America says: "You will see that we give the boys a good deal more sleep than they have in public schools in England. I was myself at Cheltenham College for five years and $I$ feel convinced that we were not allowed enough time for sleep. At this school boys up to 15 are allowed $10 \frac{1}{4}$ hours; over 15, if not in the sixth, nine hours 20 minutes; sixth form, eight hours 55 minutes." So that in this school more sleep is given to the sixth form boys than in many English schools is allowed to children of 13 and 14 . The headmaster of another school (this time an Englishman), who was for 14 years assistant master at one of the great schools, where the hours of quiet in the dormitories are given as eight and a quarter and eight and three-quarters in summer and winter respectively, writes to me: "As to sleep, the fact that I aim at nine [hours] for myself will show you my belief on the subject. In the winter we have no work before breakfast. The bigger boys get nine and a half hours' sleep in the winter, for silence is enacted at 10 P.n. . . The little boys are in bed at 9, are called at 7.30 , and are down at 8 , so they get $10 \frac{1}{2}$."

To turn to the medical aspect of the case Dr. Clement Dukes, whose writings on school hygiene are widely consulted by all educational authorities, in the address which he gave before the Congress on School Hygiene in February last (1905), said: "If we follow nature, during the years of formation and development adequate sleep must not only be permitted but enforced. When puberty arrives and new functions are being established more sleep still is imperative, as is also the case in cold weather. The long hours of work demanded of the younger children, with the short time allowed for sleep could not be continued if the scheme were in force all the year round, as there would be no children left at the school. The vacations save a complete breakdown." He concludes by saying: "It is both unwise and unnatural to arrange suitable hours of work and sleep for the seniors in schools, to which juniors have to conform with serious injury to their present and their future. According to Dr. Clouston there is a decreasing degree of staying power manifest during the last 30 years (i.e., since the Education Act of 1870) on the part of the brain, to the extent of about 40 per cent. It is a question for us all to consider what share, if any, schools have in this terrible fact with the excessive hours of work in the early years of childhood, and totally inadequate amount of sleep during the same period of life." Dr. T. B. Hyslop, senior physician to Bethlem Royal Hos. pital and King Edward's Schools (London and Witley), is not less emphatic. "My experience in Bethlem," he says, "tells me that the question of sleep is worthy of our most serious attention. ...... 90 per cent. of the cases admitted to Bethlem since the year 1820 have suffered from insomnia. That one of the essentials of life (as sleep is) should be so prone to be disordered is significant that there is a fault in our economy and this fault seems to arise from the fact that few, if any, of those who have charge of our boys and girls pay any attention to the cultivation of the habit of sleep." The stress and strain of modern life necessitates increased brain activity, and in order that the mental energies may last it is obvious that brain rest should be obtained. Insomnia, brain fatigue, neurasthenia, are products of the last few decades and nearly all the cases I have to deal with have histories of overwork and inability to obtain a sufficient amount of rest. Oh! if only the people could be made to understand that the cultivation of the habit of sleep means an investment or insurance against the mental and nervous maladies of the present day...... Each decade sees us becoming more brainy, but the alertness of our youths and adolescents is shorter lived and premature degenerations are the almost inevitable outcome of a false economy in the use and abuse of brain power. On several occasions I have spoken about the tendency to later hours and their train of
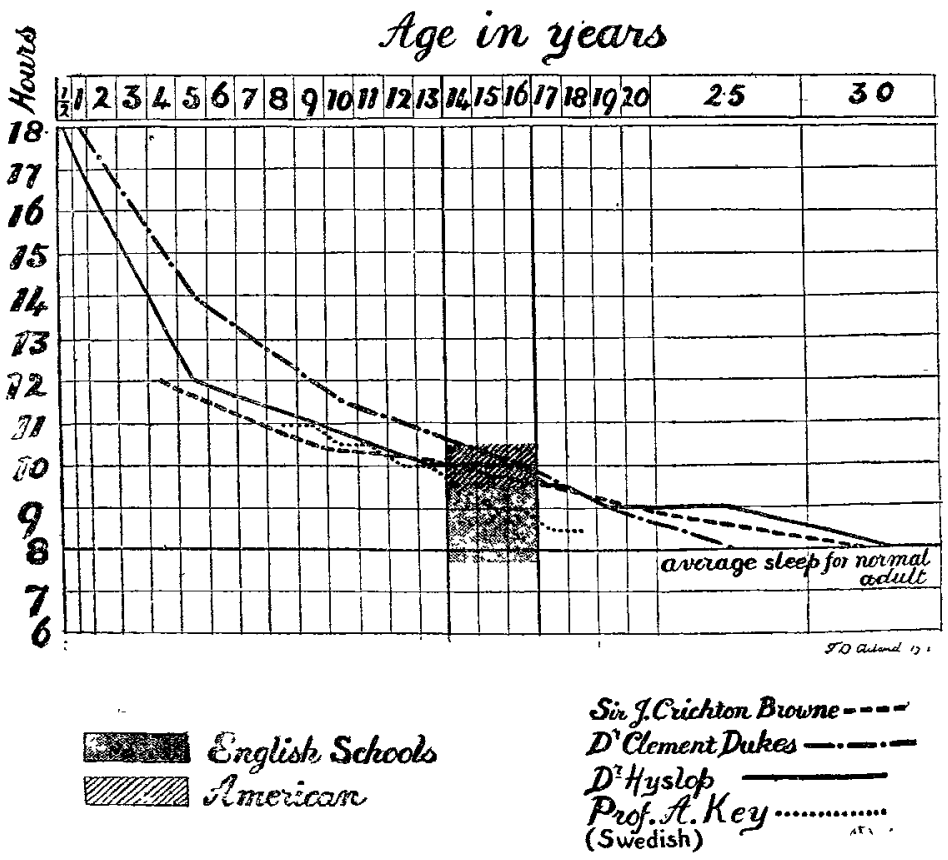

This chart has been compiled from figures given by Sir J. Crichton-Browne ("Health and the Nervous System," Cassell's Book of Health, p. 296); Dr. Clement Dukes (Health Cassell's Book of Health, p. 296) ; Dr. Clement Dukes (Health at School, fourth edition, Rivingtons, 1905, p. 130); Professor A. Key* (Handbuch der Schulbygiene Burgerstein und Netolitzky, IIte. Aufl., Jena, 1902, p. 692! ; from an unpublisher diagram by Dr. Hyslop, and from data obtained rom the various public schools (cf. Tables I. and II.) In 23 out of the $40 \mathrm{Hnglish}$ schools of which I have obtained particulars, the hours of sleep given to the younger boys fall short of the minimum for all or part of the vear, and even the hours given to the older boys are in many instances

Professor Key allows one hour in the dormitory for rising and going to bed in addition to the hours given in his table.

evils, but the people will awaken themselves to the truth only when it is too late. ...... The increase in mental and nervous instability demands a reversal of the engines of education, and $I$ would regard sleep as the best preservation

6 Sleep in Relation to Education, by Dr. Clement Dukes, phrsician to Rugby School, author of Health at School. Fourth edition. Rivingtons, 1905.

During the discussion on this paper Br. G. H. Savage, consulting physician to Guy's Hospital, late medical superintendent to Bethlem Royal Hospital, spoke strongly to the same effeet. 
against the stress and strain of life and all the incidental conditions which make so many succumb in adult life. I have been some considerable time in making out a chart of the relationship of sleep to age; the reason for the various estimates are based upon deeper considerations than those of temporary expediency (see Chart). ...... I have had charge of 480 children, 11 to 15 years of age, so I have had opportunities of studying the question."

I should like here to call attention to two papers by Dr. Hyslop on "Mental Hygiene in Childhood" 8 and "The National Basis of Education." In these be points ont the evils of defective brain rest and he draws attention to the symptoms of what he calls mental indigestion, such as nightmares, night terrors, somnambulism, epilepsy, and even convulsions, and he speaks strongly on the culpable ignorance of those who are responsible for the education of children, inasmuch as they attribute the formidable array of neuroses with which the expert has to deal merely to constitutional defect, whereas, in fact, it is to the system of education rather than to the child that the maladies are due. Ignorance on these points, he concludes, is all the more reprehensible, because it is within the power of those responsible to obtain enlightenment from those who, having had the necessary medical training, are well qualified to advise them.

One of your members, himself a distinguished medical officer of a great public school, writes: "The arrangements which still obtain in many schools under this head (the hours of sleep) are no doubt physiologically wrong and economically unsound. It is obviously unreasonable that the child who, if his parents are at all wise, is allowed his fair allowance of sleep within proper hours, during the holidays at home, should be docked of a substantial part of his physiological income just when the call upon it is greatest, that is at school."

Next let me quote Sir James Crichton-Browne whose work on Orer-pressure in Schools is so well known. He writes : "You will be doing a public service by calling attention to the matter and by insisting on the importance of the vis dormativa in early years." $\mathrm{He}$ adds that he has not the shadow of a doubt that obvious and immediate harm results from short hours of sleep and is certain that much and very serious deferred harm may result from them. He continues : "Highly strung, sensitive boys suffer at once from loss of sleep. ..... The more stolid and stable boys suffer covertly in slight retardation of brain growth and intelligence, not so obvious but real enough. Sleep is more intimately connected with brain growth than with brain function. In the years of highest cerebral activity in adult life least sleep is required, in the years of low functional activity, but rapid growth, most. ...... I have noted as one of the causes of the physical deterioration that is, I believe, going on, insuffciency and dislocation of sleep. This is a sleepless age and more and more ..... we are turning night into day. The sleep of the rising generation is being seriously interfered with, abbreviated, and broken, and the inevitable consequence must be a rich crop of 'neurotism' and a general lowering of the level of intelligence."

These are strong words coming from a trained observer who has devoted more than 30 years to the study of disorders of the nervous system and who has made a special study of the evil results of over-pressure in schools which has deservedly received wide recognition. 23 years ago he wrote: "From birth when the brain is growing rapidly and when life is almost a continuous sleep, onwards till manhood when brain growth is at an end and when only a third of existence is (or ought to be) given to sleep, the increment of growth progressively diminishes, and par passu with this diminution in growth goes a reduction in the demand for sleep made by the system, so it might perhaps be said that eight hours in the 24 constitute the amount of reparative sleep needed by the full-grown brain and that all sleep beyond that amount prior to maturity is germinal sleep connected with processes of growth and development." 10

If this is a reasonable statement of the case it follows that to give the adolescent brain a bare eight hours' sleep is to stint the growing boy not only in the time ne zded for the processes of development and growth but to

8 Clinical Journal, 1904, vol. xxv., No. 8, pp. 113-22.

${ }^{9}$ A paper read before the Beckenham Medical Society, Jan. 13th, 1905. and shortly to be published.

cin the Book of Health. Cassell and Co. Pp. 293, 294. impair the efficiency of those higher nerve centres on whose well-being the future of the boy's intellectual standard so largely depends. Nothing is more certain than that the improvement of the community turns upon the proper care and management of its children and no temporary success in obtaining scholarships at the universities and other distinctions, which are so often unreasonably accepted as the standard of efficiency of a school, can compensate in any way for the disregard of the plain teachings of physiology as to the relations of work and sleep which must in the long run be obeyed if the mass of ordinary boys are to be turned out fitted in the best way of which they are capable for taking their places as citizens of a great empire. Dr. Welldon, formerly headmaster of Harrow, draws attention in one of his speeches to a fact which had impressed itself upon himnamely, the number of clever brilliant boys he had known who in after life had absolutely disappeared. As Dr. Dukes remarks: "He did not recognise that these boys' immature brain tissue was exhausted before manhood." 11 In these days when athletics count for so much at school it is well to recognise that ample sleep is needed not only to render the brain and nervous system fit for active work but that it is not less necessary to maintain the muscles of an active boy in good sound condition. ${ }^{12}$ Those who train men of picked physique for great races know this well and insist (as one of the most celebrated oarsmen of our generation informs me) on a good eight and a half to nine hours' sleep for those in training. These men, wise in their generation, do not see how much the crew can stand, nor run any avoidable risk of tiring them out before the final struggle has begun, a wisdom which it is to be feared is not always to be found in those who have the training of our youth for the great race of life.

TABLE III.-Synopsis of Hours of Undisturbed Rest given to the Younger Boys in 40 English Public Schools.

\begin{tabular}{|c|c|c|c|c|}
\hline Class. & $\begin{array}{l}\text { No. of } \\
\text { Schools. }\end{array}$ & Ample hours. & Moderate hours. & Short hours. \\
\hline A. & 5 & $\begin{array}{l}9 \frac{3}{4} \text { to } 10 \text { or more } \\
\text { all the year. }\end{array}$ & - & - \\
\hline B. & 2 & $\begin{array}{l}9 \frac{1}{2} \text { to } 10 \text { the two } \\
\text { winter terms. }\end{array}$ & 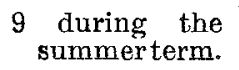 & - \\
\hline C. & 7 & $\begin{array}{c}9 \frac{1}{2} \text { to } 10 \text { for a few } \\
\text { weeks only. }\end{array}$ & $\begin{array}{l}9 \text { to } 9 \frac{1}{2} \text { the chief } \\
\text { part of the year. }\end{array}$ & - \\
\hline D. & 3 & - & $\begin{array}{l}9 \text { to } 9 \frac{1}{4} \text { all the } \\
\text { year. }\end{array}$ & - \\
\hline E. & 7 & - & $\begin{array}{l}9 \text { to } 9 \frac{1}{2} \text { the two } \\
\text { winter terms. }\end{array}$ & $\begin{array}{l}8 \text { to } 8 \frac{1}{2} \text { during the } \\
\text { summer term. }\end{array}$ \\
\hline F. & 8 & - & $\begin{array}{l}9 \text { to } 9 \frac{1}{2} \text { for a few } \\
\text { weeks only. }\end{array}$ & $\begin{array}{l}8 \text { to } 8 \frac{1}{2} \text { the chief } \\
\text { part of the year. }\end{array}$ \\
\hline G. & 8 & - & - & $\begin{array}{l}8 \text { to } 8 \frac{3}{4} \text { or less } \\
\text { all the year. }\end{array}$ \\
\hline
\end{tabular}

It is interesting to note that there appear to be only five out of the 40 English schools which come up to the highest standard, whilst in all five of the great American schools with which I have been put into communication, through the kindness of Professor W. Osler, the approved hours are given to the younger boys-namely, from nine and a half to ten ; and further, four of the headmasters of these schools have expressed the opinion quite emphatically that these hours are desirable for the well-being of the boys. 50 medical experts, medical officers of schools, and others, have expressed a decided opinion that ample hours of sleep are needful for growing boys. Amongst these are included all in this country who (as far as I can ascertain) have written definitely in standard works on the question of sleep: Sir James Crichton-Browne, Dr. Clement Dukes, Professor Bradbury, Dr. Hyslop, Professor McKendrick, and Professor Sherrington, and besides these there are many

11 "Remedies for the Needless Injury to Children involved in the Present System of School Education." An address delivered before th Incorporated Association of Heaūmasters at their annual general meeting held in London. Rivingtons, 1899. Pp. 7, 8 .

12 I have received an interesting letter from Mr. C. B. Fry on this point. Although he was at a school where he got nine hours' sleep he writes that he felt that he never had his sleep out and required more than he got; so much did he crave for sleep that often for the first week or so of the holidays he would go to bed about 10 P.M. and sleep till one or two o'clock and sometimes even till five o'clock th next day. He adds that this was not laziness but was absolutely a
natural paying of himself back : he felt that he had lived on his capital. 
whose names are honoured in English medicine and whose opinions cannot be disregarded on such a question as this. Such are Sir William H. Broadbent, Sir Thomas Barlow, Sir Lauder Brunton, Sir Dyce Duckworth, Professor Clifford Allbutt (Cambridge), Professor Osler (Oxford), Dr. Collier, Dr. Dickinson, Dr. Goodhart, Dr. Savage, Dr. Eustace Smith, besides 15 medical officers of the most celebrated public schools in Fngland. It would be impossible to enumerate all, but the list includes many who have made a special study of diseases of children and disorders of the nervous system as well as those who have specially considered the subject in relation to modern education. 27 have given the number of hours which they consider best; the remainder do not definitely specify the number of hours but speak emphatically in more general terms.

\section{TABLE IV. (A).-Showing the Hours of Sleep desirable for} Growing Boys.

27 medical officers of schools and other medical experts advise the following hours :-

$$
\begin{aligned}
& 9 \text { advocate } 10 \text { hours. } \\
& 8 \quad, \quad 9 \frac{1}{2} \text { or } 9 \frac{1}{2} \text { to } 10 . \\
& 6 \quad \text { " } \quad 9 \text { to } 9 \frac{1}{2} \text { or } 9 \text { to } 10 \\
& 4 \quad, \quad 9 \text { as a "minimum }
\end{aligned}
$$

Not a single medical expert has advocated less than nine hours.

\section{TABLE IV. (B).-Summary of Opinions received from}

\section{Medical Officers of Schools.}

15 are in favour of longer hours. All from schools which give short hours of sleep during all or part of the year.

13 consider the hours of sleep sufficient in their schools.

In 10 of these schools nine hours or more are given throughout the year.

In two for part of the year.

In one only are short hours given throughout the year.

6 replies indefinite.

6 replies not received.

It may, I think, be rightly claimed that there is conclusive evidence to show that both on physiological and medical grounds ample hours of sleep are necessary for the best development of growing boys and that up to 16 years of age from nine and a half to ten hours of undisturbed rest in bed in winter, and from nine to nine and a half in summer, would be in no way excessive. Do they in practice get this amount and if they do not do they feel the strain? The first question may without hesitation be answered in the negative, since although in a limited number of schools some of the small boys may be in their dormitories for the length of time named there is practically no possibility, from one cause or another, of their having anything like this amount of sleep. Hours in dormitory do not, of course, represent hours of sleep, though from some of the replies I have received it would appear that they are reckoned as such. Even the number of hours in bed often do not represent hours of sleep where the boys are in dormitories, unless order is really maintained, as it appears to be in some few schools with good discipline and on the training ships. But in a good many dormitories, besides the talking and "ragging" which goes on, there are other serious disturbances of sleep which efficiently break the rest of all but sound sleepers. Amongst these have to be reckoned not only the turning up of lights when the older boys come to bed (so that although the small boys may get to bed earlier they have the light in their eyes until the older boys are settled) but also the practice of not having the dormitory reasonably darkened, a point which Sir Williarn Gull considered to be of great importance. Thus the hours are not only curtailed by the daylight waking the boys long before it is time for them to rive, but the quality of the sleep obtained is in the case of light sleepers seriously interfered with.

It cannot be questioned that the quality of sleep is influenced by darkness and that to insure the most complete rest to the nervous system it is necessary that sleep should not only be unbroken by noise but also by the exclusion of strong light from the room. It is also important that dormitories and cubicles should be properly warmed and ventilated. Sir James Crichton-Browne writes : "A certain degree of bodily comfort is essential to the good quality of sleep, and quality is almost as important as quantity." These may seem trivial details but they are worthy the attention of those who have the well-being of young boss at heart. There are few blessings given to mankind cruater than a capacity for good sound sleep; it makes work easier and more effective and probably more than ans. thing else enables the happy possessor of the faculty to meet the strains which he must encounter in the struggle for existence. It is surely worth while for those who have charge of the young not only to give ample hours of sleep but to see that as far as possible the arrangements are such as to insure that the sleep is not disturbed, as it often is, by preventable or unnecessary causes. Those who have given attention to the subject know the importance of this. "Quality," writes Dr. Hyslop, "is as essential as quantity for the building up the preservative power of sleep." Dr. Savage also lass special stress on this point and it was a favourite maxim of Sir James Paget.

In few schools would it appear that any attempt is made to encourage the habit of getting proper sleep; in fact, it seems to be assumed that the less sleep a boy can do with the better it will be for him and the hardier he will become. Such an idea is, I believe, entirely fallacious. It is not much more difficult to educate a boy in good habits than in bad ones, and of the two there can be no kind of doubt that the boy who has acquired the habit of sleeping well will in the long run have greater staying power than he who has not learnt the need for giving his nervous system sufficient rest. One of my correspondents writes: "Happy the man who in the days of his youth has contracted the habit of sound regular sleep. The headmasters should really, I think, offer prizes to the best sleepers.'

From all sides I have learned that short hours of sleep do often press heavily on the younger boys and are of no possible advantage to them. None are more emphatic on this point than the masters of private schools who keep in touch with the boys after they leave, and especially those who have sons of their own at the public schcols, from whom they hear the truth They are not quite so innocent as one of my corre. spondents who told me that he did not believe the small boys wanted more sleep because they never complained to the headmaster! In two great schools I am assured that boys are not infrequently taken into the sanatorium, not because they are ill, but because they are tired out. One distinguished member of our profession whom $I$ can remember as a boy at the top of one of our great public schools writes: "As to sleep, I fully agree with you that boys, especially young boys, do not get enough at school A little boy can honestly sleep the clock round and is all the better for ten hours. I remember that $m y$ condition as a little boy at school was one of perpetual want of sleep. I used to go to sleep at all sorts of inconvenient moments through the day in consequence. Another thing is the disturbance of the sleep of little boys by the elder boys coming to bed later. ...... That ought not to be." As showing the importance of what has been written I should like to emphasise the fact that 15 medical officers attached to 12 of the great schools in which the hours of sleep possible for the younger boys are amongst the shortest (Table IV., B) have expressed the opinion that longer hours of sleep are desirable. I have been told by one of the few who have questioned the soundness of my contention that it is clear that the younger boys do not want more sleep because if they are sent to bed early they chatter instead of going to s'eep. But that they do want more sleep is clear from the fact that the have to be often roused out of deep sleep next morning and dress half asleep in silence (as I have been assured they often do), too weary to show any of that exuberance of spirits which is natural to the healthy boy. If it is a fact that small boys chatter as a rule when they lave a chance of going to sleep it would only show that in this, as in other matters, they need education. If in other branches of the school curriculum, as in this question of sleep, the decision as to what was good for them were left entirely to the boys the whole plan of education would, fear, very speedily be dislocated. Is it not the duty of those responsible for the order in a house to see that after a reasonable time for going to bed has been allowed silence is really enforced?

It is difficult to ascertain the precise hours of sleep which can be obtained in any particular school, since local conditions vary. as, for instance, in one house silence in the dormitories may be really enforced at a given hour, whilst in others no account may be taken of the fact that prefect keep a light, or elder boys cause a disturbance by going to bed long after the normal hour given as that at which thr younger boys are settled. It is also clear that the hours of 
sleep generally adopted at any particular school can be modified by the house masters to some extent. The compilation therefore of such a table as Table I. is one of peculiar difficuity and the hours given must be taken to represent the general rule of the school rather than as applicable to any particular house in that school. I have given in lable I. the hours of sleep allotted to the older boys as well as to the younger ones and it will be seen that they also are often too short.

The general results of my inquiry, after careful sifting of the evidence, reveal some curious facts. In the first place, the hours of quiet which appear to be given to boys from 13 to 15 or 16 seem to range from $7 \frac{3}{4}$ to $10 \frac{1}{2}$ in summer and from $8 \frac{1}{4}$ to $10 \frac{1}{2}$ in winter. Again, winter hours vary from a few weeks in some schools to 24 weeksi.e., the two winter terms, in others. There is also a wide diversity in the hours at which the boys are called.

TABLE V. (A).-Showing Hours at n.hioh the Boys are Called in 40 English Public Schools.

No. of schools. Hours at which boys are called

6.0 summer term; 6.45 two winter terms.

6.15 most of the sear; $6.45-7.0$ for some weeks.

6.30 all the year.

6.30 most of the year; $6.45-7.30$ for some weeks.

6.30 summer term; $7.0-7.30$ two wint er terms.

6.30 ; not stated whether ary difference in winter.

6.45 all the year.

6.45 most of the year; $7.0-7.30$ for some weeks.

6.45 summer term; 7.30 two winter terms.

7.0 all the year.

7.0 most of the year; 7.30 for some weeks.

7.0 summer term ; $7.15-7.30$ two winter terms.

7.0 ; not stated whether any difference in wiriter.

7.15 all the year.

7.15 ; not stated whether any difference in winter.

7.30 all the year.

TABLE V. (B).-Showing Hours at which Boys are Called in Five of the Principal Ameriean sohools.

No. of schools.

Hours at which boys are called.

\subsection{0 all the sear.}

7.0 all the year.

7.0 in summer; 7.30 in winter.

Some of those who are willing to admit that the hours for sleep given in the schools with which they are connected are too short raise certain objections to increasing them. They point out that there is a difficulty in arranging different hours for boys of different ages. Such an objection cannot be regarded as a serious ore, for, after all, what can be done, and is done satisfactorily, in some schools might also be done in others.

The statement to which I have already referred, "that longer hours of sleep would encourage the luxury and selfindulgence which are eating the heart out of our English boyhood and manhood," requires consideration. If it be true, every writer on the subject of sleep in this country, as far as I can trace them, is wrong, since I am unable to find any statement in writings on school hygiene which justifies the giving of as little as eight hours' quiet in the dormitories to the younger boys or which gives any countenance to the belief that nine, nine and a half, or even ten hours is either morally or physiologically kad. Commenting on the statement just quoted the headmaster of a large school writes:

"It is strange, indeed, to find anyone so mistaken as to the causes of whatever may be wrong with the upbringing of our youth as to attribute it to over-sleep. One sympathises with him in his fight against a tendency to luxuriousness and general slackness" (as we all do) "but I apprehend that it is a pcor weapon to defy nature. We must look elsewhere for the cause." Professor George Darwin of Cambridge writes to me on the subject as follows: "If it is a question of giving up some hours in school, or giving up sleep, I say the former is immeasurably preferable. I ask fuither whether lack of due sleep is not responsible for much of the prevalent slackness in school, of which there is so much reason to complain." If it can be shown that from nine to nine and a half hours of actual sleep are a physiological necessity for the average boy it can hardly be seriously maintained that it is encousaging sloth to give it. Might it not just as well be argued that to give wholesome and sufficient food is encouraging gluttony, a comforting doctrine to those who do not care to face a difficult problem, but hardly one which is likely to satisfy parents or the boys themselves.

It is an equally unsatisfactory argument that short hours of sleep are a process of selection and lead to the survival of the fittest. This presupposes that the fittest are those who happen to need the least sleep, an wholly fallacious argument, as we all know, since those who are the least affected by a scanty allowance of brain rest during their zears of growth are often the dull heavy boys, whilst the keen, sensitive, intelligent boys are the ones to suffer. A master of one of the large public schools and one in which the hours of sleep are comparatively good, writes : "The hours of rest could profitably be somewhat lengthened. I am inclined to think that specially in the case of the clever boys this increase of rest would increase the intellectual efficiency." Again, I have been told that to allow boys to lie in ced after the hour of 6.30, which seems specially hallowed by tradition, is to encourage them in habits of idleness. This entirely depends on the hour at which the boys can get to sleep. It is no use burning the candle at both ends. To give a new version of an old proverb :-

\section{"Late to bed and early to rise,} Is neither physiological nor wise."

I believe in boys getting up early after a sufficient number of hours of sleep but not before; to allow them in the summer, when they have more play as well as their full allowance of work, to get into the habit of going to bed late is not defensible. The medical officer of a great school which stands comparatively high in this matter of sleep in consequence of the boys having separate rooms calls attention to this and says in summer he thinks the younger hoys often do not get sufficient sleep; whilst another says that in his opinion "for a young boy not to be in bed till 10 and up at 6.30 is an unduly strained life." There seems to be a strong feeling that the difficulties of getting the boys to bed early are well-nigh insuperable and that the real solution of the difficulty is the abolition of school, or of chapel and school, before breakfast, even if not in summer, certainly during the two winter terms. There is a considerable body of opinion in favour of this abolition of school or chapel before breakfast. Three eminent physicians who bave had special opportunities for arriving at a sound conclusion think the question ought to be faced and from medical officers of seven of the most important schools I have received expressions of opinion that it would be better certainly during the cold weather, if not all the jear round, to abandon this practice, which is of doubtful utility, and is open to many objections. The master whose letter I have just quoted says: "I think this addition [to sleep] would be best made in the morning, as if sent to bed too early the boys would not go to sleep but be inclined to play and talk and the net result in rest would probably be diminished ratber than increased. Boys, however, sleep quite soundly till late in the morning."

The objection to giving boys a fuller allowance of sleep which needs most consideration, is the moral one. The headmaster of one of the great public schools which bas produced many successful scholars, whilst admitting that many of the jounger boys would be the better for more sleep than they get, urges this objection; he says that longer hours would give opportunities for those evil habits which have to be guarded against and which are so rightly dreaded in any community of boys. His argument is that if the boys are tired out when they go to bed and have to be roused from sleep in the morning they will have less temptation to evil. Such an argument I believe to be not only a libel on the average healthy-minded boy but 1 cannot help thinking it to be unsound, for the reason that no one was ever made moral by being made feeble. I cannot doubt that the only way to combat this evil is to make the boys healthy, active, and vigor ous and to deal with the danger straightforwardly from the manly point of view. I would not have touched on the question but that it has been refinitely raised in the course of my inquiries and has to be faced. I consulted Sir Constantine Holman on this point. 
He has, as many of you know, been treasurer and on the council of a large public school for nearly half a century and has had wide experience in dealing with this problem; he tells me (and allows me to use his name) that physiologically it is quite certain that the younger growing boys need more sleep than those who have arrived at maturity and that an average of eight hours is needed for fully grown men in active work, whilst boys at the critical period of their development need more. He says he considers it absurd to suppose that the mere giving of an ample allowance of sleep would in any way tend to promote immorality; that, as a matter of fact, the difficulties arise at the commencement of the night and not in the morning, when the increase of sleep must be given if at all. He does not believe that with all the opportunities for evil (if the boys are so minded) the question whether they have a sufficient or insufficient amount of sleep can have any bearing whatever on the subject. This is, I believe, the common-sense view of a dificult problem; the danger cannot be avoided by aiming at weakness and repression but only by healthy teaching and inculcating self-control.

There are two other points which I must briefly mention. One is that boys are classified not by age but by place in school, so that the clever little boys, who really require longer rest than others of their age owing to the increased activity of their brains, get the shorter hours allotted to the older boys. The other is that the line between juniors and seniors seems generally to be drawn between 15 and 16 years instead of a year later. Boys up to 16 years of age are still growing and developing rapidly and need all the rest given to younger boys.

I think that I may rightly claim to have shown that in many of our schools this question of sleep has been too little considered and that the hours of sleep given to the younger boys, and I might almost say often to all the boys, are too short, whilst in others, although the needs of the younger boys have been recognised to some extent, the attempts to give them longer rest than the older ones, by sending them to bed earlier in the same dormitories, have failed for various reasons. I have tri ad to face the difficulties and answer the objections to giving longer hours of sleep and to show that physiology, medicine, and common-sense declare in no uncertain voice that to maintain the maximum intellectual and bodily efficiency of growing boys it is absolutely necessary not to stint their bodies and their nervous systems of rest. seems to me that the logical conclusion is that the younger boys should be placed in separate dormitories, under effective supervision, or if, as some believe, it is better to have boys of different ages in the same dormitories that quiet should be insured for all, say at 10 P.M., and that during the summer months boys should be called at 7 and during the two winter months at 7.30. By this means from nine to nine and a half hours of quiet could with reasonable certainty be obtained. It may be urged that I am treading on dangerous ground; some may think that an attempt is being made to upset time-honoured traditions. To this I would reply that traditions based upon circumstances of life which have passed away are not necessarily the best guides for dealing with the conditions of to-day and that to respect traditions solely because they have been approved in the past make not for national efficiency but for national decay. The hurry and stress of life in the present day are infinitely greater than they have ever been before and the alarming increase in disorders of the nerrous system is attracting the anxious consideration of those who have the best opportunities of estimating its extent. With these facts before us we ought to spare no pains to impress our convictions as to the necessity for carefully regulated hours of rest upon those who are responsible for the health and education of our boys, on whose intellectual efficiency and bodily vigour the future of this country so largely depends. In conclusion, I venture to hope that this Association may take the matter up and may be able to convince those who have the direction of our great schools that the subject of giving the younger boys ample sleep is one wbich is deserving of their most serious consideration.

Bryansten-square, $w$

Russiax Medical MeN NOT PerartTted to HOLD A CoNference. - The village and factory medical men of the Moscow province proposed to hold a conference in the local government house to discuss matters interesting to the profession, but, according to the Novoe Iremya, the legal authorities refused them the permission to do so.

\section{THE INFLUENCE OF FRUIT ON THE PRECIPITATION OF THE URIC ACID OF THE URINE.}

\author{
BY WILLIAM J. SMITH JEROME, M.A. OXON.,
} M.B. LOND.

LECTUREB IN PHARMACOLOGY IN THE UNIVERSITY OF OXFORD.

Few things perplex a patient more than the contradictory advice as to diet which is liable to be offered to him when consulting more than one medical man for the same ailment. The difference in question is doubtless due to our want of precise knowledge as to the effect of various foods, while this again is traceable, in no small degree, to the sacrifice of time and convenience demanded of those who undertake, or submit to, the experiments necessary for obtaining the desired knowledge. The subject, however, is important, and I hope through some experiments I have been making on myself to throw a little light on one or two of its many obscure points, one object of the work described below being to ascertain if there is a scientific basis for the practice, followed to some extent at any rate, of allowing certain fruits and denying others to those who suffer from uric acid calculus and gravel.

To ascertain the influence of an article of diet in in. creasing or lessening the tendency of the uric acid to spontaneous precipitation, it is of course necessary to have a means of measuring the precipitability of the acid in a given specimen of urine. If all specimens deposited uric acid on keeping the information could be obtained from a knowledge of the percentage amount of uric acid and the quantity precipitated in a given time under uniform conditions ; but many, even acid, urines may be kept for very lengthened periods by means of antiseptics without any separation of their uric acid in a solid form. It is possible, none the less, by a very simple application of the known laws controlling solution and precipitation to obtain an available and satisfactory test.

A solid like uric acid will not be deposited from its solution until its solvent is supersaturated; while supersataration, on the other hand, may be carried to a considerable extent without the occurrence of precipitation. If, however, ever so small a quantity of free uric acid is present in the solid state in such supersaturated solution, uric acid deposition will begin and continue till supersaturation has given place to saturation, equilibrium being established. The rate of deposition will vary with circumstances and is largely dependent on the surface area presented by the solid, while it is quickened by shaking, stirring, \&c. These remarks apply to solutions of free uric acid and His ${ }^{1}$ and Klemperer ${ }^{2}$ have shown that a part, even as much as 96 per cent., of the uric acid of the urine may be in this condition. Part, however, is combined with base, and this portion will not conform to the rule stated until it has been set free by the addition of some strong acid which in the old phraseology was said to take the base by virtue of its stronger affinity for this, while it is now known that the result is determined by the feebler tendency of the weaker acid (uric) to undergo ionisation. We can therefore, by adding a strong acid, free any uric acid which is combined with base and, provided that a mere grain of uric acid is present in the solid form, insure the deposition of all that is in solution over and above the point of saturation. But the strong acid serves another purposeviz., that of lowering the saturation point in accordance with the law that the solubility of an electrolyte is lessened by the addition of another electrolyte which yields an ion in common with it. Besides the free uric acid and that whicb is combined with base there is a small quantity in the form of organic combination, but as this, for the knowledge of which we are indebted to $\mathrm{His}{ }^{3}$ is not thrown down by acids, it does not need consideration in the present connexion.

The above principles are illustrated by the three follow. ing experiments, showing that while the rate of uric acid deposition is determined, ceteris paribus, by the amount of strong acid added, the quantity thrown down is independent

1 Therapie der Gegenwart, October, 1901. 2 Verhandlungen des 20 ten Congresses für Inmere Medicin, Wiesbaden, 3 Loc. cit. 